\title{
Using Hot Electrons and Hot Holes for Simultaneous Cocatalyst Deposition on Plasmonic Nanostructures
}

\author{
Evgenia Kontoleta, Alexandra Tsoukala, Sven H. C. Askes, Erwin Zoethout, Eitan Oksenberg, \\ Harshal Agrawal, and Erik C. Garnett*
}

Cite This: ACS Appl. Mater. Interfaces 2020, 12, 35986-35994

Read Online

\section{ACCESS \\ Llll Metrics \& More \\ Article Recommendations \\ Supporting Information}

ABSTRACT: Hot electrons generated in metal nanoparticles can drive chemical reactions and selectively deposit cocatalyst materials on the plasmonic hotspots, the areas where the decay of plasmons takes place and the hot electrons are created. While hot electrons have been extensively used for nanomaterial formation, the utilization of hot holes for simultaneous cocatalyst deposition has not yet been explored. Herein, we demonstrate that hot holes can drive an oxidation reaction for the deposition of the manganese oxide $\left(\mathrm{MnO}_{x}\right)$ cocatalyst on different plasmonic gold $(\mathrm{Au})$ nanostructures on a thin titanium dioxide $\left(\mathrm{TiO}_{2}\right)$ layer, excited at their surface plasmon resonance. An $80 \%$ correlation between the hot-hole deposition sites and the simulated plasmonic hotspot location is showed when considering the typical hot-hole diffusion length. Simultaneous deposition of

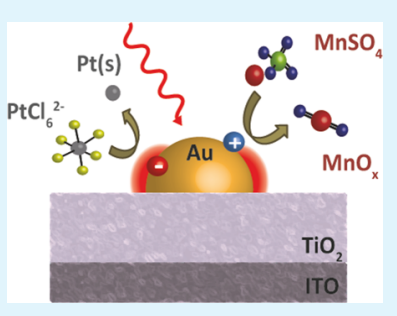
more than one cocatalyst is also achieved on one of the investigated plasmonic systems (Au plasmonic nanoislands) through the hothole oxidation of a manganese salt and the hot-electron reduction of a platinum precursor in the same solution. These results add more flexibility to the use of hot carriers and open up the way for the design of complex photocatalytic nanostructures.

KEYWORDS: hot-hole chemistry, plasmon-driven chemical reactions, photocatalysis, hot carriers, manganese oxides, photodeposition of cocatalysts

\section{INTRODUCTION}

Plasmonic nanoparticles are considered good candidates for photocatalysis mostly due to their large and tunable absorption cross sections in the visible spectrum and their ability to generate highly energetic carriers. ${ }^{1-6}$ The light-driven resonant collective oscillations of the free electrons (i.e., plasmons) in noble metal nanostructures are responsible for their unique properties. Plasmons can concentrate the light in the vicinity of the nanostructure in subwavelength volumes (i.e., hotspots) where the intensity of the electric near-field can be extremely enhanced. ${ }^{7,8}$ The location of these hotspots can be easily tuned on the same nanostructure by changing the polarization or the wavelength of the incident light. The decay of the plasmons at the hotspots, via Landau damping, can give rise to the excitation of conduction band electrons to energy states higher than the Fermi level $\left(E_{\mathrm{f}}\right)$ of the metal, with maximum energy $E_{\mathrm{f}}$ $+h \nu$. These initially nonthermal high-energy electrons (hot electrons) and their respective holes (hot holes) can be extracted from the nanostructure and react with nearby molecules by injection to their unoccupied orbitals. ${ }^{9-12}$ The energy of the photogenerated hot carriers can be tuned by changing the energy of the incident photons, which can be useful for promoting certain chemical pathways according to their energy requirements and increase the selectivity over specific chemical products. ${ }^{13-15}$ It has also been demonstrated that hot carriers have reaction rates scaling superlinearly under high photon flux and/or in dense particle systems, in contrast to conventional semiconductor photocatalysts (they usually scale with the square root of the light intensity), which can open different pathways in light-driven chemical reactions. ${ }^{16,17}$ Hot carriers have been already used for a plethora of chemical reactions such as water splitting, ${ }^{18-21} \mathrm{H}_{2}$ dissociation, ${ }^{22} \mathrm{CO}$ oxidation, ${ }^{23} \mathrm{NH}_{3}$ decomposition, ${ }^{24}$ reduction of diazonium salts, $^{25}$ and synthesis of nanomaterials. ${ }^{26,27}$

Although hot carriers in plasmonic nanoparticles seem very promising for driving chemical reactions with light, the quantum efficiency of these reactions is still very low $(\sim 1 \%) .{ }^{28}$ Hot electrons and hot holes thermalize very fast to a Fermi-Dirac distribution through electron-electron (100 fs to $1 \mathrm{ps}$ ) and electron-phonon scattering ( 1 to $10 \mathrm{ps}$ ) to finally dissipate heat to the local environment (100 ps to 10 $\mathrm{ns}){ }^{10,29,30}$ A common way to cope with these short lifetimes is to separate the hot carriers using a Schottky barrier, by adding a semiconductor (e.g., $\left.\mathrm{TiO}_{2}\right)$, which can accept the hot electrons or hot holes. ${ }^{31,32}$ The timescales of the extraction of the hot electrons (holes) to the conduction (valence) band of the semiconductor are usually much shorter than the electron-phonon scattering. ${ }^{29}$ The hot-electron flow from plasmonic Schottky nanodiodes has been directly measured,

Received: March 16, 2020

Accepted: July 16, 2020

Published: July 16, 2020 


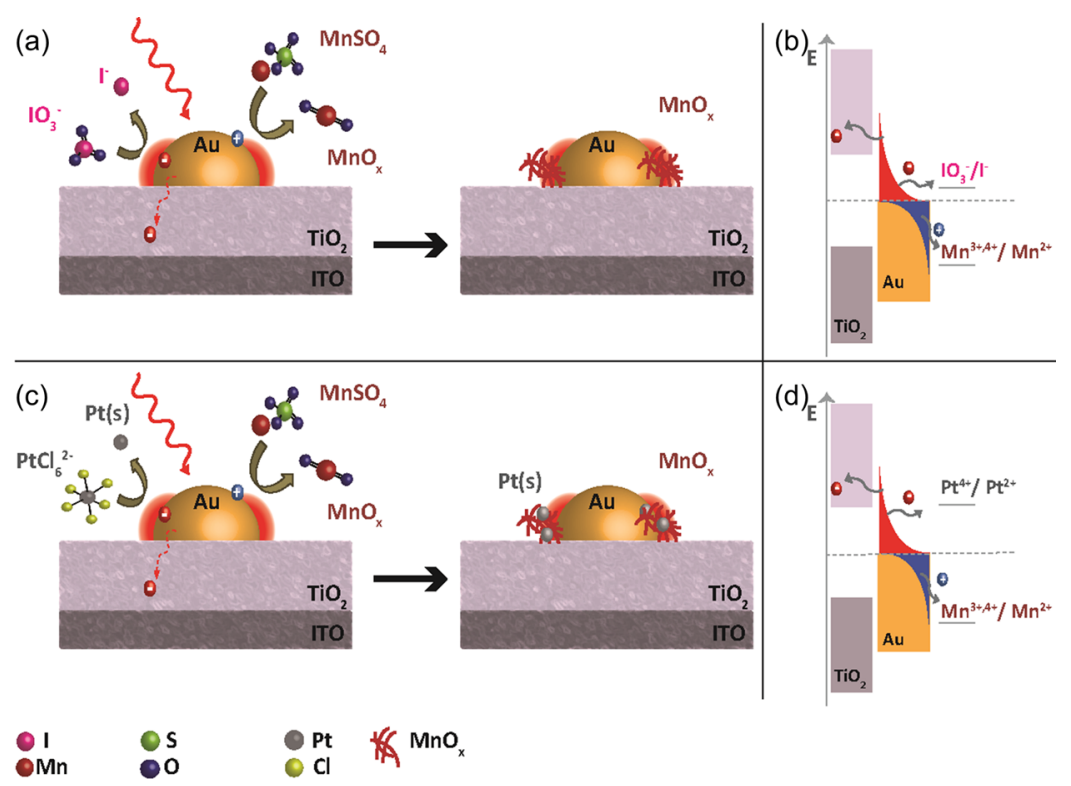

Figure 1. (a, c) Plasmonic Au nanoislands on $\mathrm{TiO}_{2}$ are excited at their surface plasmon resonance (638 nm) in an aqueous solution of (a) $\mathrm{MnSO}_{4} /$ $\mathrm{NaIO}_{3}$ or (c) $\mathrm{MnSO}_{4} / \mathrm{H}_{2} \mathrm{PtCl}_{6}$. Hot electrons and hot holes are photogenerated at the plasmonic hotspots. Hot electrons reduce $\mathrm{IO}_{3}{ }^{-}$to the soluble $\mathrm{I}^{-}$in panel (a) or $\mathrm{H}_{2} \mathrm{PtCl}_{6}$ to $\mathrm{Pt}$ solid species $\left(\mathrm{Pt}^{4+}\right.$ to $\mathrm{Pt}^{2+}$ in panel (c)), while hot holes oxidize $\mathrm{Mn}^{2+}$ to solid-state $\mathrm{MnO}_{x}\left(\mathrm{Mn}^{2+}\right.$ to $\mathrm{Mn}^{3+}$ and/or $\left.\mathrm{Mn}^{4+}\right)$. (b, d) Simplified energy diagrams where the reduction potentials of the redox reactions are depicted together with the energy levels of the Schottky junction and the Fermi-Dirac distribution of the hot carriers.

proving the increase in hot-carrier lifetime due to the formation of the Schottky junction, which allows detectable hot-electron photocurrents. ${ }^{33,34}$ For highly energy demanding chemical reactions such as water splitting, the addition of cocatalyst nanoparticles is also necessary to achieve higher photon to electron efficiencies. ${ }^{35-37}$ However, cocatalysts are often very expensive materials (e.g., $\mathrm{Pt}$ ) and they lack good optical properties. Therefore, a smart design of plasmonic/ cocatalyst nanostructures is necessary, in order to combine the optical properties of the former and the good catalytic activities of the latter. This could be achieved by the careful positioning of the cocatalyst on the surface of the plasmonic nanostructures.

The hotspots of the plasmonic nanostructures as mentioned before are the areas where the hot electrons and hot holes are mostly generated, so a cocatalyst at these locations could help the charge separation and increase the amount of carriers participating in the chemical reactions. ${ }^{18,38,39}$ Several studies have already shown that the positioning of the cocatalyst on the plasmonic hotspots can increase the efficiency of the metal nanostructure and at the same time reduce the amount of the material needed, decreasing the cost. ${ }^{27,40-42}$ In most of those studies, surfactant chemistry is used to position the cocatalyst at the corner and edge sites, where ligands have a sparse or more disordered surface coverage, providing more free surface sites for localized cocatalyst deposition. While there can be a correspondence between curvature and optical field enhancement, ${ }^{40,43}$ this approach removes the possibility of using the underlying optical resonance spatial structure, which can vary at different wavelengths, as a design parameter for the deposition. Here, we use the photogenerated hot carriers themselves to localize the formation of the cocatalysts on the plasmonic hotspots. Hot electrons have already been used for reduction reactions resulting in the deposition of catalytic $\mathrm{Pt}$ nanoparticles on plasmonic nanostructures. ${ }^{27,44,45}$ Although both types of hot carriers have been used to drive chemical reactions, ${ }^{18}$ so far the utilization of both hot carriers for the deposition of different cocatalysts has not been demonstrated. Using both hot charge carriers opens up the possibility for autonomous photocatalytic systems with optimized positioning of both oxidation and reduction cocatalysts.

In this work, Au plasmonic nanoislands are excited at their local surface plasmon resonance (LSPR) to generate hot electrons and hot holes, which are used for reduction and oxidation reactions, respectively, for the formation of two different cocatalyst materials simultaneously. First, the photodeposition of one cocatalyst is investigated using the photogenerated hot holes. The Au nanoislands prepared on a thin $\mathrm{TiO}_{2}$ anatase layer are illuminated in the presence of manganese sulfate $\left(\mathrm{MnSO}_{4}\right)$ and an electron scavenger (sodium iodate, $\mathrm{NaIO}_{3}$ ). Hot holes are used for the oxidation of $\mathrm{MnSO}_{4}$ to $\mathrm{MnO}_{x}$ (cocatalyst 1), while hot electrons are either injected to the conduction band of the nearby semiconductor layer $\left(\mathrm{TiO}_{2}\right)$ or scavenged by a sacrificial electron acceptor (Figure 1a). The simultaneous deposition of two different cocatalysts is also explored by substituting the electron scavenger with a $\mathrm{Pt}$ precursor to drive the reduction of the latter to Pt metal nanoparticles (cocatalyst 2) using the photogenerated hot electrons (Figure 1c). This approach of using all the hot carriers of plasmonic nanoparticles for the selective deposition of cocatalytic materials to synthesize nanostructures, where the optical properties of the plasmonic material are combined with the catalytic properties of the added cocatalysts, can be very promising for photocatalysis. Our results show that light can be used as a reagent in combination with plasmonic nanocatalysts to control the spatial pattern of cocatalysts via both hot electrons and hot holes.

\section{EXPERIMENTAL SECTION}

General. Chemicals were purchased from major chemical suppliers and used as received. Sample characterization was done with scanning electron microscopy (SEM; FEI Verios 460; acceleration beam 

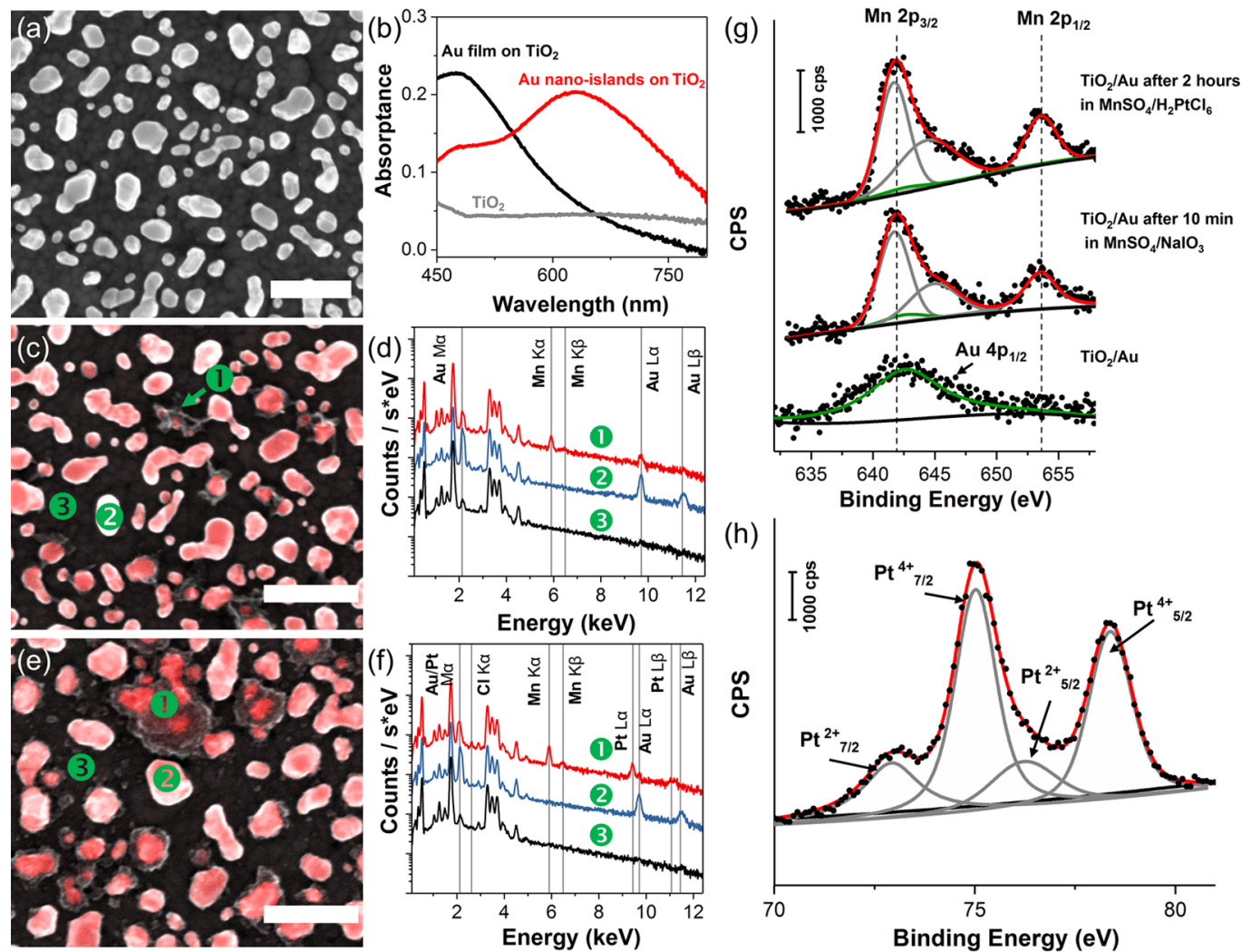

Figure 2. (a) SEM image of Au nanoislands on a $\mathrm{TiO}_{2} / \mathrm{ITO} /$ glass substrate (200 nm scale bar). (b) Absorptance spectrum of the Au nanoislands on $\mathrm{TiO}_{2}$ (red solid line, after subtracting the ITO/glass contribution), of the Au film ( $8 \mathrm{~nm}$ ) before annealing to form the Au nanoislands (black solid line) and of a $22 \mathrm{~nm}$ anatase $\mathrm{TiO}_{2}$ film (gray solid line). (c, e) SEM images of Au nanoislands after (c) $10 \mathrm{~min}$ and (e) $2 \mathrm{~h}$ illumination at 638 $\mathrm{nm}\left(0.5 \mathrm{~W} / \mathrm{cm}^{2}\right)$ in $\mathrm{MnSO}_{4} / \mathrm{NaIO}_{3}$ and $\mathrm{MnSO}_{4} / \mathrm{H}_{2} \mathrm{PtCl}_{6}$, respectively. These panels overlay SEM images from two different detectors to help differentiate between the $\mathrm{Au}$ (and $\mathrm{Pt}$ ) and $\mathrm{MnO}_{x}$ : the ICD (red false coloring), which provides mostly z-contrast (Au and $\mathrm{Pt}$ ), and the in-lens detector (grayscale), which provides mostly topographical contrast $\left(\mathrm{MnO}_{x}, \mathrm{Au}\right.$, and $\left.\mathrm{Pt}\right)$. The scale bars are $200 \mathrm{~nm}$. (d, f) EDS spectra of samples in panels $(c, e)$, respectively, where each number on the spectrum corresponds to a specific and depicted point on the SEM image. (g) XPS spectra (black dots) of the samples shown in panels (a, (c, e) in the Mn 2p region. (h) XPS spectrum of the sample in panel (e) in the Pt $4 \mathrm{f}$ region. Red lines represent cumulative fitting curves, gray lines represent individual peak fits annotated per element and oxidation state, and green lines in panel (g) represent the Au $4 \mathrm{p}_{1 / 2}$ peak. A Shirley-type baseline was used.

voltage, $5 \mathrm{kV}$; beam current, $100 \mathrm{pA})$ and energy-dispersive spectroscopy (EDS; Oxford Instruments; acceleration beam voltage, $25 \mathrm{kV}$; beam current, $100 \mathrm{pA})$. X-ray photoelectron spectroscopy (XPS) was performed using a $\mathrm{K} \alpha$ setup from Thermo Fisher Scientific that is equipped with a detector at normal incidence. The composition of the top surface was studied in a vacuum environment of $1 \times 10^{-8}$ mbar where monochromatic $\mathrm{Al} \mathrm{K} \alpha$ radiation has been used to investigate the surface. CasaXPS was used for baseline and peak fitting (with a Voigt function in a Shirley background). A UV/ vis/NIR spectrophotometer (PerkinElmer, L750) was used for acquiring the absorbance spectra.

Atomic Layer Deposition. ITO/glass substrates $(15 \times 15 \mathrm{~mm})$ were cleaned with detergent, rinsed with demineralized water, acetone, and isopropanol, and dried with a $\mathrm{N}_{2}$ stream. A thin $\mathrm{TiO}_{2}$ layer was then deposited on the substrates with atomic layer deposition in a home-built system. The first few millimeters of the sample surface were covered with a Kapton tape, in order to leave a part of the surface conductive to do the electrical connections during the photoelectrochemical characterization of the samples. The samples were positioned in the chamber on a copper plate, heated up to $100{ }^{\circ} \mathrm{C}$, and $\mathrm{TiCl}_{4}\left(\geq 99.995 \%\right.$, Sigma-Aldrich) and $\mathrm{H}_{2} \mathrm{O}$ (MilliQ) vapor pulses were injected with $18 \mathrm{~s}$ delay in between each pulse $\left(20 \mathrm{~ms}\right.$ duration for both $\mathrm{TiCl}_{4}$ and $\left.\mathrm{H}_{2} \mathrm{O}\right)$. The base pressure of the system was 0.04-0.07 mbar, while during the deposition, the pressure was kept at $1.1 \mathrm{mbar}$ with an influx of $\mathrm{N}_{2}$. After the deposition of around $22 \mathrm{~nm}$ of $\mathrm{TiO}_{2}$, which corresponded to 300 cycles $(\sim 0.07 \mathrm{~nm} /$ cycle $)$, the samples were annealed in a tube furnace in air for $3 \mathrm{~h}$ at $350{ }^{\circ} \mathrm{C}$ with a heating rate of $11{ }^{\circ} \mathrm{C} / \mathrm{min}$. A similar procedure was followed for the deposition of the alumina $\left(\mathrm{Al}_{2} \mathrm{O}_{3}\right)$ thin layers on $\mathrm{Au}$ nanoislands. In the $\mathrm{Al}_{2} \mathrm{O}_{3} \mathrm{ALD}$ process, the chamber was heated up to $250{ }^{\circ} \mathrm{C}$ and trimethylaluminum (TMA) and $\mathrm{H}_{2} \mathrm{O}$ (MilliQ) vapor pulses were injected with $18 \mathrm{~s}$ delay in between each pulse (10 ms duration for both TMA and $\mathrm{H}_{2} \mathrm{O}$ ).

$\mathrm{Au}$ Nanoisland Preparation. Plasmonic Au nanoislands on the $\mathrm{TiO}_{2}$ surface were made by sputtering (Leica EM ACE600 sputter coater) of an $8 \mathrm{~nm}$ Au film with a $0.33 \mathrm{~nm} / \mathrm{s}$ deposition rate. The current of the process was adjusted to make sure that the deposition rate is the same every time, and it was varying between 30 and 100 $\mathrm{mA}$. The thickness of the deposited Au film was monitored through a quartz crystal mounted inside the sputter coater. The annealing of the $\mathrm{Au}$ thin film was conducted in a tube furnace in air, which was brought to $300{ }^{\circ} \mathrm{C}$ with a $9.2{ }^{\circ} \mathrm{C} / \mathrm{min}$ heating rate, kept at a constant temperature for $1 \mathrm{~h}$ to form the $\mathrm{Au}$ nanoislands, and then allowed to cool down to room temperature.

Au Nanotriangle Preparation. Au nanotriangles were fabricated by nanosphere lithography on $\mathrm{TiO}_{2} / \mathrm{ITO} /$ glass substrates. A monolayer of carboxylated polystyrene (PS) spheres (bought from microParticles $\mathrm{GmbH}$, Germany) with a diameter of $\sim 527 \mathrm{~nm}$ was deposited via convective assembly in a hexagonal packing on the aforementioned substrates using a home-built setup. The sample was held by vacuum on a motorized stage, while a hydrophobic $0.5 \mathrm{~mm}$ microscopy slide was kept $\sim 100 \mu \mathrm{m}$ above it at an angle of $5^{\circ}$ with the horizontal. Ten microliters of the suspension of PS spheres in aqueous solution ( $1 \mathrm{wt} \%$ ) was dispensed at the interface between the 
substrate and the glass blade, and as a result of the capillary forces, it was quickly sucked between them. A Peltier heating element was attached underneath the vacuum stage to control the temperature, and it was maintained at $23{ }^{\circ} \mathrm{C}$ for the entire process of convective assembly. The motorized stage moved the substrate against the glass blade with a speed of $\sim 500$ to $600 \mu \mathrm{m} / \mathrm{min}$, which yielded monolayers of PS spheres on the order of $\mathrm{mm}^{2}$ area. The system is also coupled to a microscope that allows control over the whole process, and the deposition parameters can be controlled by in-house written software. After the assembly of the PS spheres on the sample, $30 \mathrm{~nm}$ of Au was evaporated at a rate of $0.01 \mathrm{~nm} / \mathrm{s}$ with a thermal evaporator (Angstrom Engineering, Amod). Finally, the PS spheres were removed from the substrate after $\sim 4 \mathrm{~min}$ of sonication in chloroform $\left(\mathrm{CHCl}_{3}\right)$, leaving only the $\mathrm{Au}$ layer in between the spheres, which corresponded to Au nanotriangles of around $112 \pm 18$ $\mathrm{nm}$ edge. The samples were rinsed with $\mathrm{H}_{2} \mathrm{O}$ before photodeposition.

Photoelectrochemical Measurements. Photoelectrochemical measurements were conducted in a three-electrode photoelectrochemical cell connected to a potentiostat (Biologic, SP-200). The sample was connected electrically to the potentiostat, as the working electrode, with a conductive aluminum tape (Advance Tapes AT521) placed on the first $2 \mathrm{~mm}$ of the sample $\left(\mathrm{TiO}_{2}\right.$ uncoated). A leakless $\mathrm{Ag} / \mathrm{AgCl}$ electrode (Mengel Engineering ED-ET072) was used as a reference electrode, and a Pt wire acted as a counter electrode. After each photoelectrochemical measurement, the samples were rinsed with $\mathrm{H}_{2} \mathrm{O}$ and dried with $\mathrm{N}_{2}$.

Wavelength-Dependent Measurements (IPCE). For the wavelength-dependent measurements, which were used for the calculation of the IPCE values, the same PEC cell was used as before (see Photoelectrochemical Measurements). The excitation source was a supercontinuum laser (Fianium WL-SC-390-3), which was made monochromatic using an acousto-optic tunable filter (AOTF, Crystal Technologies), and the illumination of the sample was performed from the back side (ITO/glass). The potentiostat was connected with the PEC cell and with a lock-in amplifier (Stanford Research Systems SR830). The current signal detected from the sample was sent through the potentiostat to the lock-in amplifier ( $100 \mathrm{mV}$ sensitivity, \pm 10 V output) with a DB9 to 8 BNC multicoaxial adapter cable. The lock-in amplifier isolated the signal coming from the light, which was chopped with a $70 \mathrm{~Hz}$ frequency, separating it from any other noises of the system. The final signal was sent back to the potentiostat where the recorded photocurrent was plotted as a function of time. Every 20 $\mathrm{s}$, the incident beam was blocked, and every $40 \mathrm{~s}$, the excitation wavelength was redshifted by $20 \mathrm{~nm}$, in order to better distinguish the photocurrent values per wavelength. This configuration was not able to give us dark current values since a lock-in amplifier was used, so every time the laser beam was blocked, no signal detection was possible.

\section{RESULTS AND DISCUSSION}

$\mathrm{Au}$ plasmonic nanoislands (Figure $2 \mathrm{a}$ ) were fabricated on a $\mathrm{TiO}_{2}$ substrate with the aim of using them for the photogeneration of hot electrons and hot holes and to drive redox reactions for the deposition of cocatalyst nanoparticles. A thin $\mathrm{TiO}_{2}$ layer $(\sim 22 \mathrm{~nm})$ was deposited on ITO/glass with atomic layer deposition at $100{ }^{\circ} \mathrm{C}$ and annealed for $3 \mathrm{~h}$ at 350 ${ }^{\circ} \mathrm{C}$ to form the anatase phase, which acts as an efficient hot electron extraction medium. ${ }^{46}$ An $8 \mathrm{~nm}$ Au film was sputtercoated on the $\mathrm{TiO}_{2}$ layer and was converted to $\mathrm{Au}$ plasmonic nanoislands after annealing for $1 \mathrm{~h}$ at $300{ }^{\circ} \mathrm{C}$ in air. The prepared $\mathrm{Au}$ nanoislands with the largest mean diameter of 67 $\pm 35 \mathrm{~nm}$ (Figure S1) have a surface plasmon resonance at $\sim 638 \mathrm{~nm}$ (Figure $2 \mathrm{~b}$ ). The samples are illuminated at the peak of their surface plasmon resonance with a laser diode $(638 \mathrm{~nm}$, $0.5 \mathrm{~W} / \mathrm{cm}^{2}$ ) to generate hot electrons and hot holes. The excitation of the plasmonic nanoislands takes place in the presence of an aqueous solution of $\mathrm{MnSO}_{4}(0.01 \mathrm{M}, \mathrm{pH}$ 5.2,
$\mathrm{N}_{2}$-purged) and $\mathrm{NaIO}_{3}(0.02 \mathrm{M})$ to facilitate the oxidation of $\mathrm{MnSO}_{4}\left(\mathrm{Mn}^{2+}\right)$ to the cocatalyst $\mathrm{MnO}_{x}$ (possible redox reactions: reactions 1 and 2) using the photogenerated hot holes. ${ }^{47,48} \mathrm{NaIO}_{3}\left(\mathrm{IO}_{3}{ }^{-}\right.$in water$)$acts as a secondary channel for hot-electron scavenging since it can be reduced to $\mathrm{I}^{-}$ (reaction 3$)^{49,50}$ by any electrons not immediately injected into $\mathrm{TiO}_{2}$. Since it has been previously determined that the hot-electron injection efficiency in $\mathrm{Au}-\mathrm{TiO}_{2}$ systems is below $40 \%$, we expect that a complimentary hot-electron scavenger such as $\mathrm{IO}_{3}^{-}$could boost the efficiency of the hot-hole photoreaction. ${ }^{51-53}$

$$
\begin{aligned}
& \mathrm{Mn}^{2+}+2 \mathrm{H}_{2} \mathrm{O}+2 \mathrm{~h}_{\text {hot }}^{+} \rightarrow \mathrm{MnO}_{2}+4 \mathrm{H}^{+} \\
& 2 \mathrm{Mn}^{2+}+3 \mathrm{H}_{2} \mathrm{O}+2 \mathrm{~h}_{\text {hot }}^{+} \rightarrow \mathrm{Mn}_{2} \mathrm{O}_{3}+6 \mathrm{H}^{+} \\
& \mathrm{IO}_{3}^{-}+6 \mathrm{e}_{\text {hot }}^{-}+3 \mathrm{H}_{2} \mathrm{O} \rightarrow \mathrm{I}^{-}+6 \mathrm{OH}^{-}
\end{aligned}
$$

SEM images (Figure $2 \mathrm{c}$ and Figure S2) taken using two different modes (in-column detector, ICD, and through the lens detector, TLD) after $10 \mathrm{~min}$ of continuous illumination of the samples reveal the formation of a new material mostly on the $\mathrm{Au}$ nanoislands and not on the $\mathrm{TiO}_{2}$ surface (see in the Figure 2 caption and Supporting Information for more details). The morphology of the newly formed material looks very similar to the photodeposited $\mathrm{MnO}_{x}$ on semiconductor crystals in the work of $\mathrm{Li}$ et al. ${ }^{48}$ Energy-dispersive X-ray spectroscopy (EDS, Figure 2d) and X-ray photoelectron spectroscopy (XPS, Figure $2 \mathrm{~g}$ ) measurements were conducted to identify the chemical composition and oxidation state of the deposited materials. The deposited compound corresponds to $\mathrm{Mn}$ ( $\mathrm{Mn}$ peak, red solid line, Figure 2d; new peaks, Figure 2g), while the binding energies of the Mn $2 \mathrm{p}_{3 / 2}(641.7$ and $644.9 \mathrm{eV})$ and Mn $2 \mathrm{p}_{1 / 2}(653.4 \mathrm{eV})$ peaks can be assigned to a mixture of $\mathrm{Mn}^{3+}\left(\mathrm{Mn}_{2} \mathrm{O}_{3}\right)$ and $\mathrm{Mn}^{4+}\left(\mathrm{MnO}_{2}\right)$ species. ${ }^{54-56}$ Note that the $\mathrm{Au} 4 \mathrm{p}_{1 / 2}$ peak (Figure $2 \mathrm{~g}$, “ $\mathrm{TiO}_{2} / \mathrm{Au}$ ", green solid line) in principle partially overlaps with the $\mathrm{Mn} 2 \mathrm{p}_{3 / 2}$ peak, but this does not prohibit the distinction between the two peaks in the illuminated sample; the Au signal is strongly suppressed in the Mn-covered sample (Figure $2 \mathrm{~g}$, " $\mathrm{TiO}_{2} / \mathrm{Au}$ after $10 \mathrm{~min}$ in $\mathrm{MnSO}_{4} / \mathrm{NaIO}_{3}$ ") due to the surface sensitivity of XPS. Illumination of the plasmonic nanoislands results in deposition of a cocatalytic material $\left(\mathrm{MnO}_{x}\right.$, with $\left.1.5 \leq x \leq 2\right)$, which is the result of hot hole-oxidized $\mathrm{Mn}^{2+}$ (control experiments discussed below).

Several control experiments were conducted to elucidate the deposition of the cocatalysts on the Au plasmonic nanoislands on $\mathrm{TiO}_{2}$. The samples were immersed in the $\mathrm{MnSO}_{4} / \mathrm{NaIO}_{3}$ electrolyte and kept in the dark for $30 \mathrm{~min}$ to exclude any spontaneous oxidation of $\mathrm{MnSO}_{4}$ due to the presence of the electron scavenger. SEM images (Figure S5) were retrieved, and no deposition of $\mathrm{MnO}_{x}$ or any other material was observed on the plasmonic nanostructures. Simple heating experiments, where the temperature of the solution was heated to $\sim 40{ }^{\circ} \mathrm{C}$ (Figure S6a) and kept constant for around $30 \mathrm{~min}$, did not result either in the formation of any material on the surface of the samples (Figure S6b), while $10 \mathrm{~min}$ of illumination led to $\mathrm{MnO}_{x}$ formation (Figure $2 \mathrm{c}$ ). Note that $40{ }^{\circ} \mathrm{C}$ is well above the surface temperature measured by a thermal camera during $0.5 \mathrm{~W} / \mathrm{cm}^{2}$ irradiation of the sample (Figure S6c) and the theoretical temperature increase expected by this light intensity and size of nanoparticles. ${ }^{57}$ The role of the electron scavenger $\mathrm{NaIO}_{3}$ in the photodeposition of $\mathrm{MnO}_{x}$ was also investigated by running experiments without it. $\mathrm{MnO}_{x}$ formation was 
observed even in the absence of $\mathrm{NaIO}_{3}$ but at a slower deposition rate, as expected (see the SEM image, Figure S7). If there is no $\mathrm{NaIO}_{3}$ present in the solution, which acts as an efficient electron acceptor, hot electrons that are not energetic enough to get injected to the conduction band of $\mathrm{TiO}_{2}$ recombine with the hot holes in the plasmonic nanostructure. Naturally, more recombination of hot carriers leads to a lower amount of deposited material.

The simultaneous deposition of two different cocatalysts $\left(\mathrm{MnO}_{x}\right.$ and $\left.\mathrm{Pt}\right)$ driven by hot-carrier chemistry was also investigated. For this experiment, all parameters were kept constant, except for replacement of the sacrificial electron scavenger $\mathrm{NaIO}_{3}$ with the $\mathrm{Pt}$ nanoparticle precursor hexachloroplatinic acid $\left(\mathrm{H}_{2} \mathrm{PtCl}_{6}\right)$, which takes the role of the hotelectron acceptor. Indeed, after $20 \mathrm{~min}$ of continuous irradiation of the samples, formation of a new material was observed by SEM images. The morphology was different from both what was observed in the absence of $\mathrm{H}_{2} \mathrm{PtCl}_{6}$ (Figure S8) and the hot electron-deposited $\mathrm{Pt}$ species on $\mathrm{Au} / \mathrm{TiO}_{2}$ nanoislands in our previous work. ${ }^{27}$ Subsequently, EDS (Figure $2 \mathrm{f}$ and EDS elemental map in Figure S9) and XPS measurements (Figure 2g,h) were conducted for the elemental analysis of the material deposited on the $\mathrm{Au}$ nanoislands. Samples illuminated for $2 \mathrm{~h}$ (Figure 2e) were used for the elemental analysis to increase the signal. EDS spectra (Figure 2f) showed that both $\mathrm{Pt}$ and $\mathrm{Mn}$ are present on the surface of the Au nanoislands after the experiment, but more information about the oxidation state of the deposited species was retrieved by the XPS analysis. The presence of new peaks in the Mn $2 p$ region in the XPS spectra, in similar binding energies as in the case of only $\mathrm{MnO}_{x}$ deposition (see Table S1), showed that the formed $\mathrm{Mn}$ is again a mixture of $\mathrm{Mn}^{3+}$ and $\mathrm{Mn}^{4+}$ species. The analysis of the Pt $4 \mathrm{f}$ XPS region (Figure $2 \mathrm{~h}$ ) shows that the $\mathrm{Pt}$ species present on the surface of the sample can be assigned to binding energies of the $\mathrm{Pt}^{2+}$ and $\mathrm{Pt}^{4+}$ doublets. The binding energies of the $\mathrm{Pt}^{2+}$ can be associated with $\mathrm{Pt}(\mathrm{OH})_{2}$ formation as the product of the reduction of a hydrolyzed product of hexachloroplatinate (possible reaction: reaction 4). The $\mathrm{Pt}^{4+}$ binding energies correspond to $\mathrm{PtO}_{2}$, which can only be the product of an oxidation reaction of another hydrolyzed product of hexachloroplatinate (reaction 5), as previously reported. ${ }^{58,59}$ As a result, the substitution of $\mathrm{NaIO}_{3}$ in the electrolyte with hexachloroplatinate leads to the deposition of a complex combination of metal oxide and hydroxide cocatalysts $\left(\mathrm{MnO}_{x}\right.$ with $1.5 \leq x \leq 2, \mathrm{Pt}(\mathrm{OH})_{2}$ and $\left.\mathrm{PtO}_{2}\right)$.

$$
\begin{aligned}
& \mathrm{Pt}(\mathrm{OH})_{2} \mathrm{Cl}_{4}{ }^{2-}+2 \mathrm{e}_{\text {hot }}^{-} \rightarrow \mathrm{Pt}(\mathrm{OH})_{2}+4 \mathrm{Cl}^{-} \\
& \mathrm{Pt}(\mathrm{OH})_{4}(\mathrm{Cl})_{2}{ }^{2-}+4 \mathrm{~h}_{\text {hot }}^{+} \rightarrow \mathrm{PtO}_{2}+4 \mathrm{H}^{+}+\mathrm{O}_{2}+2 \mathrm{Cl}^{-}
\end{aligned}
$$

The presence of $\mathrm{TiO}_{2}$ is also crucial for driving the oxidation of $\mathrm{MnSO}_{4}$ and the reduction of $\mathrm{H}_{2} \mathrm{PtCl}_{6}$. No deposition of $\mathrm{MnO}_{x}$ was observed on $\mathrm{Au}$ nanoislands on ITO/glass, in the $\mathrm{MnSO}_{4} / \mathrm{NaIO}_{3}$ electrolyte, even after $6 \mathrm{~h}$ of continuous illumination at $638 \mathrm{~nm}$ (Figure S10). Au nanoislands on ITO/ glass in $\mathrm{H}_{2} \mathrm{PtCl}_{6} / \mathrm{MnSO}_{4}$ were also illuminated for $1 \mathrm{~h}$, and again, no deposition was observed. This indicates that $\mathrm{TiO}_{2}$ probably serves a dual role in the experiment. $\mathrm{TiO}_{2}$ promotes the oxidation reaction for the formation of the cocatalysts by either providing energy states to improve hot-electron extraction or contributing to the better binding of the $\mathrm{MnSO}_{4}$ and $\mathrm{H}_{2} \mathrm{PtCl}_{6}$ complexes on the $\mathrm{TiO}_{2} / \mathrm{Au} /$ electrolyte interface. ${ }^{60,61}$ In that way, the probability of hot holes and hot electrons interacting with $\mathrm{MnSO}_{4}$ and $\mathrm{H}_{2} \mathrm{PtCl}_{6}$ at the interface of the plasmonic nanostructures and the $\mathrm{TiO}_{2}$ can be strongly enhanced.

Photoelectrochemical measurements were conducted to verify that the deposition of the cocatalysts was achieved with hot-carrier chemistry. With that aim, Au nanoislands on $\mathrm{TiO}_{2}$ were placed in a three-electrode photoelectrochemical cell (see simplified schematic in Figure $3 a$ ) to explore any

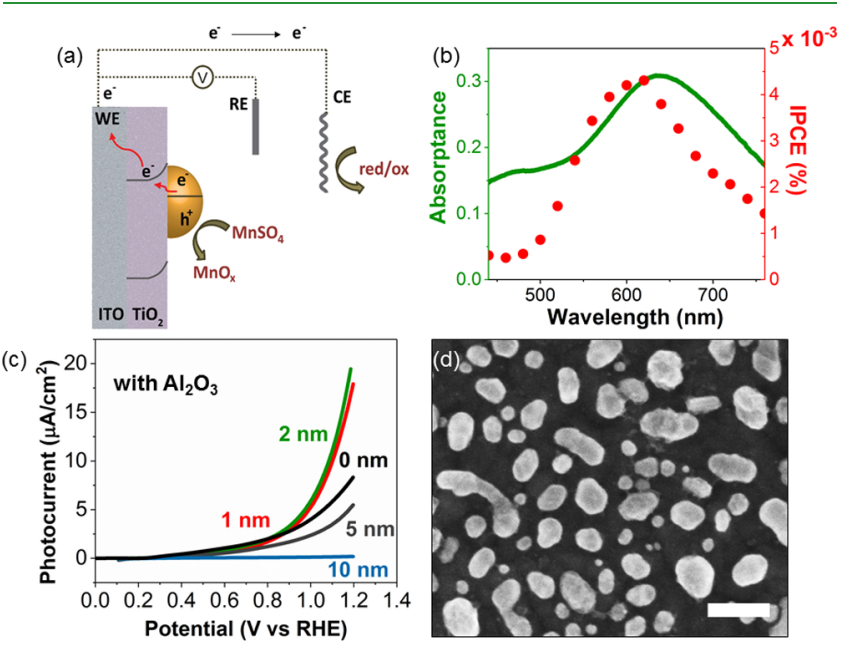

Figure 3. (a) Simplified schematic of the three-electrode photoelectrochemical system used for retrieving the data in the image in panel (b). WE stands for the working electrode (i.e., the sample), CE stands for the counter electrode (Pt wire), and RE stands for the reference electrode $(\mathrm{Ag} / \mathrm{AgCl})$. (b) Incident photon-to-current efficiency (IPCE, red circles) of $\mathrm{Au}$ nanoislands on a $\mathrm{TiO}_{2} / \mathrm{ITO} /$ glass substrate in an aqueous $\mathrm{MnSO}_{4}$ solution ( $\mathrm{pH} 5.2,0.01 \mathrm{M}$ ) and the respective absorptance spectrum (green solid line) of the same sample. (c) Photocurrent density vs potential curves of $\mathrm{Au}$ nanoislands on $\mathrm{TiO}_{2} / \mathrm{ITO} /$ glass as prepared (black solid line, "0 $\mathrm{nm}$ ") and coated with 1 (red solid line, " $1 \mathrm{~nm}$ "), 2 (green solid line, "2 $\mathrm{nm}$ "), 5 (gray solid line, " $5 \mathrm{~nm}$ "), and $10 \mathrm{~nm}$ (blue solid line, "10 $\mathrm{nm}$ ") of $\mathrm{Al}_{2} \mathrm{O}_{3}$ excited at $638 \mathrm{~nm}\left(0.5 \mathrm{~W} / \mathrm{cm}^{2}\right)$ in the presence of $\mathrm{MnSO}_{4}(\mathrm{pH} 5.2,0.01 \mathrm{M})$. (d) SEM image of Au nanoislands on $\mathrm{TiO}_{2} / \mathrm{ITO} /$ glass coated with $1 \mathrm{~nm}$ of $\mathrm{Al}_{2} \mathrm{O}_{3}$ after 20 min excitation at $638 \mathrm{~nm}\left(0.5 \mathrm{~W} / \mathrm{cm}^{2}\right)$ in the presence of $\mathrm{MnSO}_{4}$ aqueous solution $(\mathrm{pH} 5.2,0.01 \mathrm{M})$ without applying any potential. The scale bar is 100 $\mathrm{nm}$.

correlation of the generated photocurrent with the optical properties of the nanostructures (absorptance). In our previous work, a direct correlation between hot-electron generation and Pt nanoparticle formation was found. Therefore, the reaction that was mostly investigated here was the oxidation of $\mathrm{MnSO}_{4}$ to $\mathrm{MnO}_{x}$ in the absence of the electron scavenger, in order to collect as many hot electrons as possible through an external electrical circuit. During these experiments, a potential was applied to the sample (working electrode) with respect to a reference electrode $(\mathrm{Ag} / \mathrm{AgCl})$, while the current flow to a counter electrode (a Pt wire) was recorded to monitor the electron consumption by the chemical reaction. The $\mathrm{Au}$ nanoislands on $\mathrm{TiO}_{2} / \mathrm{ITO} /$ glass were excited with a lowintensity supercontinuum laser at different wavelengths in the presence of $\mathrm{MnSO}_{4}(0.01 \mathrm{M}, \mathrm{pH} 5.2)$, at an applied potential of $0.4 \mathrm{~V}$ versus reversible hydrogen electrode (open-circuit value of the sample tested, i.e., without additional electrical bias to the system). At each excitation wavelength, the photocurrent was measured (Figure S11) and used for the 

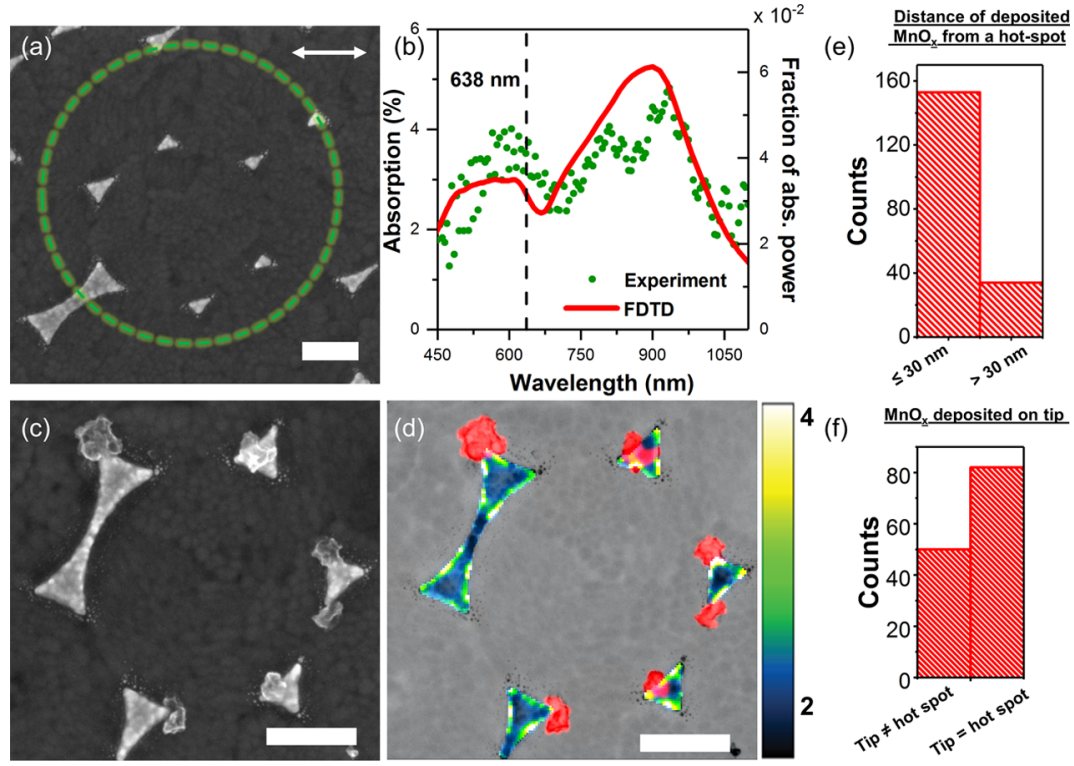

4 (f)

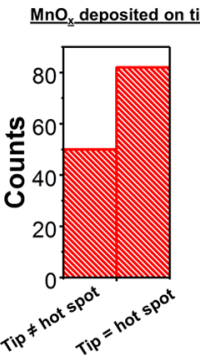

Figure 4. (a) SEM image of Au nanotriangles on $\mathrm{TiO}_{2} / \mathrm{ITO} /$ glass prepared with nanosphere lithography. Green circle corresponds to the illumination spot during absorption measurements (white arrow corresponds to the incident light polarization). (b) Absorption spectra (green dots) of the 5-6 nanotriangles inside the green circle in the image in panel (a) retrieved with integrating sphere microscopy and the average FDTD-simulated fraction of the absorbed power spectrum of $163 \mathrm{Au}$ nanotriangles (red solid line), which were imported to the simulation file as SEM images. (c) SEM image of Au nanotriangles after illumination for $10 \mathrm{~min}$ at $638 \mathrm{~nm}$ in $\mathrm{MnSO}_{4} / \mathrm{NaIO}_{3}(0.01 \mathrm{M} / 0.02 \mathrm{M}$, $\mathrm{pH} 5.2$ ). (d) Overlap of the simulated absorbed power map (see color bar) and location of $\mathrm{MnO}_{x}$ deposition sites (red) together with the respective negative SEM image of the nanotriangles in grayscale. More data sets can be found in the Supporting Information (Figure S17). The amount of $\mathrm{MnO}_{x}$ deposits on 163 $\mathrm{Au}$ nanotriangles correlated with (e) distance from a plasmonic hotspot. (f) Amount of $\mathrm{MnO}_{x}$ deposits on a nanotriangle's tip and correlation with the nature of the tip as a hotspot. All scale bars are $200 \mathrm{~nm}$.

calculation of the incident photon-to-current efficiency (IPCE, see in the Supporting Information for more information) of the samples. IPCE values were plotted as a function of the wavelength together with the absorptance spectrum of the same sample (Figure 3b). The peak of the IPCE values matches quite well with the LSPR of the Au nanoislands with the exception of the short wavelength region, which corresponds to interband transitions of Au. These transitions lead to excited electrons with energy close to the Fermi level and do not have enough energy to get transferred to the conduction band of $\mathrm{TiO}_{2}$. In this case, there is no separation of the hot electrons from the hot holes and fast recombination of the hot carriers could limit the oxidation of $\mathrm{Mn}^{2+}$ since less hot holes reach the electrolyte. ${ }^{62}$ The IPCE peak seems also blueshifted and more narrow compared to the absorptance spectrum of the Au nanoislands. This could be due to the fact that smaller particles on the sample, which absorb light in shorter wavelengths, generate more energetic hot holes than bigger nanoparticles or that the smaller particles have a higher quantum yield due to the smaller transport distance. ${ }^{63}$

$\mathrm{Au}$ nanoislands on $\mathrm{TiO}_{2}$ were coated with 1,2 , 5, and 10 nm-thick $\mathrm{Al}_{2} \mathrm{O}_{3}$ layers with atomic layer deposition, to further investigate the photodeposition mechanism and rule out any thermal effects. The thickness of the deposited $\mathrm{Al}_{2} \mathrm{O}_{3}$ layer during the ALD process was confirmed through transmission electron microscopy (TEM) imaging of Au colloids drop-cast on TEM grids as the reference (Figure S12). Coating the plasmonic nanostructures with an insulating layer can prohibit the injection of the hot holes to the electrolyte, except in the case where hot holes are tunneling through the insulating layer or transferred via pinholes or oxide defects. On the other hand, $10 \mathrm{~nm}$ of $\mathrm{Al}_{2} \mathrm{O}_{3}$ should not substantially change the temperature at the solution interface. Therefore, a decrease in photocurrent with increasing oxide thickness would provide further evidence that hot carriers rather than thermal effects are responsible for the photodeposition. The photocurrent of samples with different $\mathrm{Al}_{2} \mathrm{O}_{3}$ thicknesses was recorded as a function of the applied potential (Figure 3c), in the same three-electrode photoelectrochemical cell mentioned above, in the presence of $\mathrm{MnSO}_{4}$. The photocurrent of the samples initially increases up to $2 \mathrm{~nm}$ and then rapidly decreases with increasing $\mathrm{Al}_{2} \mathrm{O}_{3}$ thickness. This is consistent with the competing effects of improved adhesion of $\mathrm{Au}$ nanoislands to the surface with increasing ALD thickness (Figure S13) and decreased photocurrent from inhibited charge transport at larger thicknesses. It was observed that $1 \mathrm{~nm} \mathrm{Al}_{2} \mathrm{O}_{3}$-coated $\mathrm{Au}$ nanoislands presented higher stability during electrochemical measurements (potential scans) than the uncoated ones. SEM images (Figure S13) after a photocurrent versus potential measurement showed lower adhesion of the uncoated $\mathrm{Au}$ nanoislands on the $\mathrm{TiO}_{2}$ surface. The less amount of plasmonic $\mathrm{Au}$ nanoislands on the surface of the sample could be the explanation of the lower photocurrent density of a $0 \mathrm{~nm}$ $\mathrm{Al}_{2} \mathrm{O}_{3}$ (uncoated) sample compared to $1-2 \mathrm{~nm} \mathrm{Al} \mathrm{O}_{3}$ ones. Already after the addition of few nanometers of an insulating layer, tunneling should be constrained, but in our case, a thickness of $10 \mathrm{~nm}$ of $\mathrm{Al}_{2} \mathrm{O}_{3}$ is needed to make the photocurrent negligible (i.e., minimize the amount of hot holes reaching the $\mathrm{Al}_{2} \mathrm{O}_{3}$ /electrolyte interface). Trimethylaluminum oxide ( $\mathrm{ALD}$ precursor for $\mathrm{Al}_{2} \mathrm{O}_{3}$ deposition) does not bind well on the Au surface, so probably a deposition of 1-5 $\mathrm{nm}$ of $\mathrm{Al}_{2} \mathrm{O}_{3}$ results in some pinholes on the $\mathrm{Au}$ nanoislands that penetrate through the entire layer. ${ }^{64}$ The addition of thicker layers of $\mathrm{ALD} \mathrm{Al}_{2} \mathrm{O}_{3}$ before current is eliminated has also been observed in halide perovskite solar cells recently. ${ }^{65}$ The dependence of the photocurrent on the thickness of the 
insulating layer provides additional verification that the oxidation of $\mathrm{Mn}^{2+}$ to $\mathrm{MnO}_{x}$ is the result of a hot hole rather than a purely thermal or chemical reaction mechanism.

$\mathrm{Au}$ nanoislands are a very good system to monitor the hothole chemical reaction due to the high coverage of the sample and the easily detectable photocurrent but do not have welldefined hotspots. ${ }^{66}$ However, plasmonic nanotriangles (Figure 4a) with an average side of $112 \pm 18 \mathrm{~nm}$ and around $30 \mathrm{~nm}$ height (Figure S14) fabricated with nanosphere lithography allow us to investigate the location of the deposition sites of one of the cocatalysts $\left(\mathrm{MnO}_{x}\right)$ and correlate them with the plasmonic hotspots. The absorption spectrum of the prepared $\mathrm{Au}$ nanotriangles on $\mathrm{TiO}_{2} / \mathrm{ITO} /$ glass (green circles in Figure $4 \mathrm{~b}$ and Figure S15) was retrieved with integrating sphere microscopy, a technique developed previously by our group. ${ }^{67}$ Finite-difference time-domain (FDTD) simulations based on backscattered electron images (see the Supporting Information for more information and Figure S16) were used to extract the average fraction of absorbed power (Figure $4 b$, red solid line) of 163 individual $\mathrm{Au}$ nanotriangles as well as the location of their plasmonic hotspots (Figures S16d and S17). The samples were illuminated also at $638 \mathrm{~nm}\left(0.5 \mathrm{~W} / \mathrm{cm}^{2}\right)$, in one of their surface plasmon resonance peaks, for $10 \mathrm{~min}$ in the $\mathrm{MnSO}_{4} /$ $\mathrm{NaIO}_{3}$ electrolyte to repeat the $\mathrm{MnO}_{x}$ deposition. SEM images after the illumination of the samples (Figure 4c) showed that $\mathrm{MnO}_{x}$ was deposited on the surface of the plasmonic nanostructures. This specific wavelength was chosen due to the higher energy of the photogenerated hot holes compared to the ones generated at the dipolar peak $(800-1000 \mathrm{~nm})$, in order to maximize the probability of driving the oxidation of $\mathrm{MnSO}_{4}$ and the comparability with the previous experiment. Illumination of the Au nanotriangles was also conducted at a different wavelength $\left(808 \mathrm{~nm}, 0.11 \mathrm{~W} / \mathrm{cm}^{2}\right.$ for $\left.1 \mathrm{~h}\right)$, but no deposition of $\mathrm{MnO}_{x}$ was observed (Figure S18). This could be explained by the lower energy of the photogenerated holes at this excitation wavelength, which is not enough to drive the chemical reaction in similar timescales as at $638 \mathrm{~nm}$. At 808 $\mathrm{nm}$, the energy of the hot electrons is probably not enough to facilitate their transfer to the conduction band of $\mathrm{TiO}_{2}$. As a result, the population of hot electrons in the $\mathrm{Au}$ nanostructure at $808 \mathrm{~nm}$ is higher compared with the hot electron population at $638 \mathrm{~nm}$. The higher the population of hot electrons remaining in the $\mathrm{Au}$ nanostructure (nonextracted), the higher the recombination rate of the hot charges, and the less available hot holes to drive the chemical reaction.

SEM images of the Au nanotriangles after the illumination of the samples were compared with the simulated hotspots to investigate any correlation of the latter with the deposition sites of the cocatalyst. From a population of 163 nanotriangles, with $82 \%$ of them covered with one or two $\mathrm{MnO}_{x}$ deposits, $57 \%$ of the deposited $\mathrm{MnO}_{x}$ was directly overlapping with a plasmonic hotspot from the corresponding FDTD simulation (Figure S19a). When we account for a typical hot-hole diffusion length radius of $30 \mathrm{~nm}$ in $\mathrm{Au}^{68}{ }^{68} 80 \%$ of the $\mathrm{MnO}_{x}$ deposits are located within this distance (Figure 4e). This may indicate that the initial nucleation site of the catalyst particle may be located within $30 \mathrm{~nm}$ of the hotspot and acts as a hothole trap for subsequently created hot holes. Therefore, we see only one or two $\mathrm{MnO}_{x}$ deposits per particle. It is also observed that most of the $\mathrm{MnO}_{x}$ deposits are located on the $\mathrm{Au}$ nanotriangle tip (Figure S19b). However, the majority of the tips with a $\mathrm{MnO}_{x}$ deposit are indeed a plasmonic hotspot
(Figure 4f) originating from optical field enhancement due to a sharp curvature.

\section{CONCLUSIONS}

In summary, we showed that both types of hot carriers generated in plasmonic nanostructures can be utilized for simultaneous reduction and oxidation of different cocatalyst species. Hot hole-assisted deposition of $\mathrm{Mn}$ oxides and hot electron-assisted formation of $\mathrm{Pt}$ species were conducted on plasmonic $\mathrm{Au}$ nanoislands excited at their surface plasmon resonance. $\mathrm{Au}$ nanotriangles were also used as a platform to investigate the spatial localization of the deposition of the cocatalyst materials driven by hot-hole oxidation reactions. We showed that deposition sites can be controlled by engineering the location of plasmonic hotspots, with $80 \%$ fidelity. Such solid-state deposition can be used to visualize hot-carrier dynamics, including diffusion, and contribute to the lightdriven design of hierarchical nanomaterials. The deposition experiments show that direct contact with $\mathrm{TiO}_{2}$ is critical for hot-hole chemistry to occur; an additional electron acceptor can enhance the reaction rate. We believe that photocatalytic processes such as solar fuel production or wastewater treatment, where more than one cocatalyst is necessary for the chemical reactions involved, could benefit from the tailored design possible with plasmonically generated hierarchical nanomaterials. Hot carrier-assisted cocatalyst formation and spatial separation on the same plasmonic nanostructure could be the next step toward enhanced photocatalytic efficiencies.

\section{ASSOCIATED CONTENT}

\section{Supporting Information}

The Supporting Information is available free of charge at https://pubs.acs.org/doi/10.1021/acsami.0c04941.

Description of the IPCE calculation (plus presentation of the IPCE data as-retrieved), details about the FDTD simulations and image processing, supplementary figures including sample characterization (EDS map, SEM, XPS raw data, AFM, and TEM), and control experiments (PDF)

\section{AUTHOR INFORMATION}

\section{Corresponding Author}

Erik C. Garnett - Center for Nanophotonics, AMOLF, 1098 XG Amsterdam, Netherlands; 이이이.org/0000-0002-91588326; Email: E.Garnett@amolf.nl

\section{Authors}

Evgenia Kontoleta - Center for Nanophotonics, AMOLF, 1098 XG Amsterdam, Netherlands; 이이.org/0000-0002-33271523

Alexandra Tsoukala - Center for Nanophotonics, AMOLF, 1098 XG Amsterdam, Netherlands

Sven H. C. Askes - Center for Nanophotonics, AMOLF, 1098 XG Amsterdam, Netherlands; 이이.org/0000-0001-65383645

Erwin Zoethout - Dutch Institute for Fundamental Energy Research (DIFFER), 5612 AJ Eindhoven, Netherlands

Eitan Oksenberg - Center for Nanophotonics, AMOLF, 1098 XG Amsterdam, Netherlands; 이이이.org/0000-0001-94623986 
Harshal Agrawal - Center for Nanophotonics, AMOLF, 1098

XG Amsterdam, Netherlands; 이이. orcid.org/0000-0002-51063947

Complete contact information is available at: https://pubs.acs.org/10.1021/acsami.0c04941

\section{Notes}

The authors declare no competing financial interest.

\section{ACKNOWLEDGMENTS}

We want to thank Dr. Andrea Baldi and his group (Dutch Institute for Fundamental Energy Research) for the useful discussion. This work is part of the research program of Foundation for Fundamental Research on Matter (FOM), which is financially supported by the Netherlands Foundation for Scientific Research (NWO).

\section{REFERENCES}

(1) Boriskina, S. V.; Ghasemi, H.; Chen, G. Plasmonic Materials for Energy: From Physics to Applications. Mater. Today 2013, 16, 375386.

(2) Cushing, S. K.; Wu, N. Progress and Perspectives of PlasmonEnhanced Solar Energy Conversion. J. Phys. Chem. Lett. 2016, 7, 666675.

(3) Leong, K. H.; Aziz, A. A.; Sim, L. C.; Saravanan, P.; Jang, M.; Bahnemann, D. Mechanistic Insights into Plasmonic Photocatalysts in Utilizing Visible Light. Beilstein J. Nanotechnol. 2018, 9, 628-648.

(4) Cheng, H.; Fuku, K.; Kuwahara, Y.; Mori, K.; Yamashita, H. Harnessing Single-Active Plasmonic Nanostructures for Enhanced Photocatalysis under Visible Light. J. Mater. Chem. A 2015, 3, 52445258.

(5) Wang, P.; Huang, B.; Dai, Y.; Whangbo, M. H. Plasmonic Photocatalysts: Harvesting Visible Light with Noble Metal Nanoparticles. Phys. Chem. Chem. Phys. 2012, 14, 9813-9825.

(6) Linic, S.; Christopher, P.; Ingram, D. B. Plasmonic-Metal Nanostructures for Efficient Conversion of Solar to Chemical Energy. Nat. Mater. 2011, 10, 911-921.

(7) Kelly, K. L.; Coronado, E.; Zhao, L. L.; Schatz, G. C. The Optical Properties of Metal Nanoparticles: The Influence of Size, Shape, and Dielectric Environment. J. Phys. Chem. B 2003, 107, 668677.

(8) Schuller, J. A.; Barnard, E. S.; Cai, W.; Jun, Y. C.; White, J. S.; Brongersma, M. L. Plasmonics for Extreme Light Concentration and Manipulation. Nat. Mater. 2010, 9, 193-204.

(9) Govorov, A. O.; Zhang, H.; Demir, H. V.; Gun'Ko, Y. K. Photogeneration of Hot Plasmonic Electrons with Metal Nanocrystals: Quantum Description and Potential Applications. Nano Today 2014, 9, 85-101.

(10) Brongersma, M. L.; Halas, N. J.; Nordlander, P. PlasmonInduced Hot Carrier Science and Technology. Nat. Nanotechnol. 2015, 10, 25-34.

(11) Park, J. Y.; Kim, S. M.; Lee, H.; Nedrygailov, I. I. Hot-ElectronMediated Surface Chemistry: Toward Electronic Control of Catalytic Activity. Acc. Chem. Res. 2015, 48, 2475-2483.

(12) Cortés, E.; Xie, W.; Cambiasso, J.; Jermyn, A. S.; Sundararaman, R.; Narang, P.; Schlücker, S.; Maier, S. A. Plasmonic Hot Electron Transport Drives Nano-Localized Chemistry. Nat. Commun. 2017, 8, 14880.

(13) Zhang, X.; Li, X.; Zhang, D.; Su, N. Q.; Yang, W.; Everitt, H. O.; Liu, J. Product Selectivity in Plasmonic Photocatalysis for Carbon Dioxide Hydrogenation. Nat. Commun. 2017, 8, 14542.

(14) Xiao, Q.; Sarina, S.; Waclawik, E. R.; Jia, J.; Chang, J.; Riches, J. D.; Wu, H.; Zheng, Z.; Zhu, H. Alloying Gold with Copper Makes for a Highly Selective Visible-Light Photocatalyst for the Reduction of Nitroaromatics to Anilines. ACS Catal. 2016, 6, 1744-1753.

(15) Kale, M. J.; Avanesian, T.; Xin, H.; Yan, J.; Christopher, P. Controlling Catalytic Selectivity on Metal Nanoparticles by Direct
Photoexcitation of Adsorbate-Metal Bonds. Nano Lett. 2014, 14, $5405-5412$

(16) Christopher, P.; Xin, H.; Marimuthu, A.; Linic, S. Singular Characteristics and Unique Chemical Bond Activation Mechanisms of Photocatalytic Reactions on Plasmonic Nanostructures. Nat. Mater. 2012, 11, 1044-1050.

(17) Olsen, T.; Schiøtz, J. Origin of Power Laws for Reactions at Metal Surfaces Mediated by Hot Electrons. Phys. Rev. Lett. 2009, 103, 238301.

(18) Mubeen, S.; Lee, J.; Singh, N.; Krämer, S.; Stucky, G. D.; Moskovits, M. An Autonomous Photosynthetic Device in Which All Charge Carriers Derive from Surface Plasmons. Nat. Nanotechnol. 2013, 8, 247-251.

(19) Robatjazi, H.; Bahauddin, S. M.; Doiron, C.; Thomann, I. Direct Plasmon-Driven Photoelectrocatalysis. Nano Lett. 2015, 15, $6155-6161$

(20) Qian, K.; Sweeny, B. C.; Johnston-Peck, A. C.; Niu, W.; Graham, J. O.; Duchene, J. S.; Qiu, J.; Wang, Y. C.; Engelhard, M. H.; Su, D.; Stach, E. A.; Wei, W. D. Surface Plasmon-Driven Water Reduction: Gold Nanoparticle Size Matters. J. Am. Chem. Soc. 2014, 136, 9842-9845.

(21) Hou, B.; Shen, L.; Shi, H.; Kapadia, R.; Cronin, S. B. Hot Electron-Driven Photocatalytic Water Splitting. Phys. Chem. Chem. Phys. 2017, 19, 2877-2881.

(22) Mukherjee, S.; Libisch, F.; Large, N.; Neumann, O.; Brown, L. V.; Cheng, J.; Lassiter, J. B.; Carter, E. A.; Nordlander, P.; Halas, N. J. Hot Electrons Do the Impossible: Plasmon-Induced Dissociation of $\mathrm{H}_{2}$ on Au. Nano Lett. 2013, 13, 240-247.

(23) Kim, S. M.; Lee, S. J.; Kim, S. H.; Kwon, S.; Yee, K. J.; Song, H.; Somorjai, G. A.; Park, J. Y. Hot Carrier-Driven Catalytic Reactions on Pt-CdSe-Pt Nanodumbbells and $\mathrm{Pt} / \mathrm{GaN}$ under Light Irradiation. Nano Lett. 2013, 13, 1352-1358.

(24) Zhou, L.; Swearer, D. F.; Zhang, C.; Robatjazi, H.; Zhao, H.; Henderson, L.; Dong, L.; Christopher, P.; Carter, E. A.; Nordlander, P.; Halas, N. J. Quantifying Hot Carrier and Thermal Contributions in Plasmonic Photocatalysis. Science 2018, 362, 69-72.

(25) Nguyen, V. Q.; Ai, Y.; Martin, P.; Lacroix, J. C. PlasmonInduced Nanolocalized Reduction of Diazonium Salts. ACS Omega 2017, 2, 1947-1955.

(26) Zhai, Y.; DuChene, J. S.; Wang, Y. C.; Qiu, J.; Johnston-Peck, A. C.; You, B.; Guo, W.; Diciaccio, B.; Qian, K.; Zhao, E. W.; Ooi, F.; Hu, D.; Su, D.; Stach, E. A.; Zhu, Z.; Wei, W. D. Polyvinylpyrrolidone-Induced Anisotropic Growth of Gold Nanoprisms in PlasmonDriven Synthesis. Nat. Mater. 2016, 15, 889-895.

(27) Kontoleta, E.; Askes, S. H. C.; Garnett, E. C. Self-Optimized Catalysts: Hot-Electron Driven Photosynthesis of Catalytic Photocathodes. ACS Appl. Mater. Interfaces 2019, 11, 35713-35719.

(28) Cortés, E. Efficiency and Bond Selectivity in Plasmon-Induced Photochemistry. Adv. Opt. Mater. 2017, 5, 1700191.

(29) Zhang, Y.; He, S.; Guo, W.; Hu, Y.; Huang, J.; Mulcahy, J. R.; Wei, W. D. Surface-Plasmon-Driven Hot Electron Photochemistry. Chem. Rev. 2018, 118, 2927-2954.

(30) Saavedra, J. R. M.; Asenjo-Garcia, A.; García De Abajo, F. J. Hot-Electron Dynamics and Thermalization in Small Metallic Nanoparticles. ACS Photonics 2016, 3, 1637-1646.

(31) Tatsuma, T.; Nishi, H.; Ishida, T. Plasmon-Induced Charge Separation: Chemistry and Wide Applications. Chem. Sci. 2017, 8, 3325-3337.

(32) Wu, B.; Liu, D.; Mubeen, S.; Chuong, T. T.; Moskovits, M.; Stucky, G. D. Anisotropic Growth of $\mathrm{TiO}_{2}$ onto Gold Nanorods for Plasmon-Enhanced Hydrogen Production from Water Reduction. J. Am. Chem. Soc. 2016, 138, 1114-1117.

(33) Lee, Y. K.; Jung, C. H.; Park, J.; Seo, H.; Somorjai, G. A.; Park, J. Y. Surface Plasmon-Driven Hot Electron Flow Probed with MetalSemiconductor Nanodiodes. Nano Lett. 2011, 11, 4251-4255.

(34) Lee, H.; Lee, H.; Park, J. Y. Direct Imaging of Surface PlasmonDriven Hot Electron Flux on the Au Nanoprism $/ \mathrm{TiO}_{2}$. Nano Lett. 2019, 19, 891-896. 
(35) Tanaka, A.; Nakanishi, K.; Hamada, R.; Hashimoto, K.; Kominami, H. Simultaneous and Stoichiometric Water Oxidation and $\mathrm{Cr}(\mathrm{VI})$ Reduction in Aqueous Suspensions of Functionalized Plasmonic Photocatalyst $\mathrm{Au} / \mathrm{TiO}_{2}-\mathrm{Pt}$ under Irradiation of Green Light. ACS Catal. 2013, 3, 1886-1891.

(36) Swearer, D. F.; Zhao, H.; Zhou, L.; Zhang, C.; Robatjazi, H.; Martirez, J. M. P.; Krauter, C. M.; Yazdi, S.; McClain, M. J.; Ringe, E.; Carter, E. A.; Nordlander, P.; Halas, N. J. Heterometallic AntennaReactor Complexes for Photocatalysis. Proc. Natl. Acad. Sci. U. S. A. 2016, 113, 8916-8920.

(37) Aslam, U.; Chavez, S.; Linic, S. Controlling Energy Flow in Multimetallic Nanostructures for Plasmonic Catalysis. Nat. Nanotechnol. 2017, 12, 1000-1005.

(38) Sousa-Castillo, A.; Comesaña-Hermo, M.; Rodríguez-González, B.; Pérez-Lorenzo, M.; Wang, Z.; Kong, X. T.; Govorov, A. O.; Correa-Duarte, M. A. Boosting Hot Electron-Driven Photocatalysis through Anisotropic Plasmonic Nanoparticles with Hot Spots in Au$\mathrm{TiO}_{2}$ Nanoarchitectures. J. Phys. Chem. C 2016, 120, 11690-11699.

(39) Sambur, J. B.; Chen, T. Y.; Choudhary, E.; Chen, G.; Nissen, E. J.; Thomas, E. M.; Zou, N.; Chen, P. Sub-Particle Reaction and Photocurrent Mapping to Optimize Catalyst-Modified Photoanodes. Nature 2016, 530, 77-80.

(40) Zheng, Z.; Tachikawa, T.; Majima, T. Single-Particle Study of Pt-Modified Au Nanorods for Plasmon-Enhanced Hydrogen Generation in Visible to near-Infrared Region. J. Am. Chem. Soc. 2014, 136, 6870-6873.

(41) Zou, N.; Chen, G.; Mao, X.; Shen, H.; Choudhary, E.; Zhou, X.; Chen, P. Imaging Catalytic Hotspots on Single Plasmonic Nanostructures via Correlated Super-Resolution and Electron Microscopy. ACS Nano 2018, 12, 5570-5579.

(42) Michaels, A. M.; Jiang; Brus, L. Ag Nanocrystal Junctions as the Site for Surface-Enhanced Raman Scattering of Single Rhodamine 6G Molecules. J. Phys. Chem. B 2000, 104, 11965-11971.

(43) Ortiz, N.; Zoellner, B.; Hong, S. J.; Ji, Y.; Wang, T.; Liu, Y.; Maggard, P. A.; Wang, G. Harnessing Hot Electrons from Near IR Light for Hydrogen Production Using Pt-End-Capped-AuNRs. ACS Appl. Mater. Interfaces 2017, 9, 25962-25969.

(44) Forcherio, G. T.; Baker, D. R.; Boltersdorf, J.; Leff, A. C.; McClure, J. P.; Grew, K. N.; Lundgren, C. A. Targeted Deposition of Platinum onto Gold Nanorods by Plasmonic Hot Electrons. J. Phys. Chem. C 2018, 122, 28901-28909.

(45) Kim, N. H.; Meinhart, C. D.; Moskovits, M. Plasmon-Mediated Reduction of Aqueous Platinum Ions: The Competing Roles of Field Enhancement and Hot Charge Carriers. J. Phys. Chem. C 2016, 120, 6750-6755.

(46) Zhu, L.; Lu, Q.; Lv, L.; Wang, Y.; Hu, Y.; Deng, Z.; Lou, Z.; Hou, Y.; Teng, F. Ligand-Free Rutile and Anatase $\mathrm{TiO}_{2}$ Nanocrystals as Electron Extraction Layers for High Performance Inverted Polymer Solar Cells. RSC Adv. 2017, 7, 20084-20092.

(47) Busch, M.; Wang, R. B.; Hellman, A.; Rossmeisl, J.; Grönbeck, $\mathrm{H}$. The Influence of Inert Ions on the Reactivity of Manganese Oxides. J. Phys. Chem. C 2018, 122, 216-226.

(48) Li, R.; Zhang, F.; Wang, D.; Yang, J.; Li, M.; Zhu, J.; Zhou, X.; Han, H.; Li, C. Spatial Separation of Photogenerated Electrons and Holes among $\{010\}$ and $\{110\}$ Crystal Facets of $\mathrm{BiVO}_{4}$. Nat. Commun. 2013, 4, 1432.

(49) Tian, Y.; Shi, X.; Lu, C.; Wang, X.; Wang, S. Charge Separation in Solid-State Gold Nanoparticles-Sensitized Photovoltaic Cell. Electrochem. Commun. 2009, 11, 1603-1605.

(50) Maeda, K. Z-Scheme Water Splitting Using Two Different Semiconductor Photocatalysts. ACS Catal. 2013, 3, 1486-1503.

(51) Furube, A.; Du, L.; Hara, K.; Katoh, R.; Tachiya, M. Ultrafast Plasmon-Induced Electron Transfer from Gold Nanodots into $\mathrm{TiO}_{2}$ Nanoparticles. J. Am. Chem. Soc. 2007, 129, 14852-14853.

(52) Du, L.; Furube, A.; Yamamoto, K.; Hara, K.; Katoh, R.; Tachiya, M. Plasmon-Induced Charge Separation and Recombination Dynamics in Gold- $\mathrm{TiO}_{2}$ Nanoparticle Systems: Dependence on $\mathrm{TiO}_{2}$ Particle Size. J. Phys. Chem. C 2009, 113, 6454-6462.
(53) Tian, Y.; Tatsuma, T. Mechanisms and Applications of Plasmon-Induced Charge Separation at $\mathrm{TiO} 2$ Films Loaded with Gold Nanoparticles. J. Am. Chem. Soc. 2005, 7632.

(54) Kumar, S. R. S.; Hedhili, M. N.; Alshareef, H. N.; Kasiviswanathan, S. Correlation of Mn Charge State with the Electrical Resistivity of Mn Doped Indium Tin Oxide Thin Films. Appl. Phys. Lett. 2010, 97, 111909.

(55) Ilton, E. S.; Post, J. E.; Heaney, P. J.; Ling, F. T.; Kerisit, S. N. XPS Determination of Mn Oxidation States in Mn (Hydr)Oxides. Appl. Surf. Sci. 2016, 366, 475-485.

(56) Nesbitt, H. W.; Banerjee, D. Interpretation of XPS Mn(2p) Spectra of Mn Oxyhydroxides and Constraints on the Mechanism of $\mathrm{MnO}_{2}$ Precipitation. Am. Mineral. 1998, 83, 305-315.

(57) Baffou, G.; Quidant, R. Nanoplasmonics for Chemistry. Chem. Soc. Rev. 2014, 43, 3898-3907.

(58) Zhang, F.; Chen, J.; Zhang, X.; Gao, W.; Jin, R.; Guan, N.; Li, Y. Synthesis of Titania-Supported Platinum Catalyst: The Effect of $\mathrm{PH}$ on Morphology Control and Valence State during Photodeposition. Langmuir 2004, 20, 9329-9334.

(59) Wenderich, K.; Mul, G. Methods, Mechanism, and Applications of Photodeposition in Photocatalysis: A Review. Chem. Rev. 2016, $116,14587-14619$.

(60) Macyk, W.; Burgeth, G.; Kisch, H. Photoelectrochemical Properties of Platinum(IV) Chloride Surface Modified $\mathrm{TiO}_{2}$. Photochem. Photobiol. Sci. 2003, 2, 322-328.

(61) Wang, S.; Gao, Y.; Miao, S.; Liu, T.; Mu, L.; Li, R.; Fan, F.; Li, C. Positioning the Water Oxidation Reaction Sites in Plasmonic Photocatalysts. J. Am. Chem. Soc. 2017, 139, 11771-11778.

(62) Khurgin, J. B. How to Deal with the Loss in Plasmonics and Metamaterials. Nat. Nanotechnol. 2015, 10, 2-6.

(63) Manjavacas, A.; Liu, J. G.; Kulkarni, V.; Nordlander, P. Plasmon-Induced Hot Carriers in Metallic Nanoparticles. ACS Nano 2014, 8, 7630-7638.

(64) Weimer, A. W. Particle Atomic Layer Deposition. J. Nanopart. Res. 2019, 21, 9.

(65) Koushik, D.; Verhees, W. J. H.; Kuang, Y.; Veenstra, S.; Zhang, D.; Verheijen, M. A.; Creatore, M.; Schropp, R. E. I. High-Efficiency Humidity-Stable Planar Perovskite Solar Cells Based on Atomic Layer Architecture. Energy Environ. Sci. 2017, 10, 91-100.

(66) Pavaskar, P.; Theiss, J.; Cronin, S. B. Plasmonic Hot Spots: Nanogap Enhancement vs Focusing Effects from Surrounding Nanoparticles. Opt. Express 2012, 20, 14656-14662.

(67) Mann, S. A.; Sciacca, B.; Zhang, Y.; Wang, J.; Kontoleta, E.; Liu, H.; Garnett, E. C. Integrating Sphere Microscopy for Direct Absorption Measurements of Single Nanostructures. ACS Nano 2017, 11, 1412-1418.

(68) Narang, P.; Sundararaman, R.; Atwater, H. A. Plasmonic Hot Carrier Dynamics in Solid-State and Chemical Systems for Energy Conversion. NANO 2016, 5, 96-111. 